\title{
Greener Synthesis of Chitosan/Acrylic Acid (AA) Hydrogel and Its Application as Drying Agent for Organic Solvents and Crude Oil Fractions
}

\author{
N.Bhullar ${ }^{1}$, M. Bahl ${ }^{2}$, S.Kumar ${ }^{3},{ }^{4}$ K. Kumari and D. Sud ${ }^{5}$ \\ ${ }^{1,4}$ Department of Chemical Engineering, ${ }^{2,3,5}$ Department of Chemistry, \\ Sant Longowal Institute of Engineering and Technology, (Deemed University), \\ Longowal 148106, Sangrur, Punjab, India \\ E mail: suddhiraj@gmail.com
}

\begin{abstract}
The present study reports the greener synthesis of biopolymer chitosan / acrylic acid hydrogel $(C A / A A)$ using ultrasonic radiations and its applications for removal of water from organic solvents and crude oil fractions. Chitosan -acrylic acid hydrogel was prepared by polymerization of chitosan with monomer acrylic acid in the presence of initiator (K2S2O8) upon exposure to ultrasonic radiations. CA/AA was characterized by Fourier transform infrared spectra analysis (FTIR), X-ray diffraction (XRD), and Thermo gravimetric analysis (TGA). Swelling studies on CA/AA shows the hydrophilic behavior for the synthesized hydrogel. Further investigations were carried out to assess the potential of CAH for removal of water from organic solvent and crude oil fractions. reactor (at $\left.35^{\circ} \mathrm{C}\right)$ ) were operated with same reactor configuration.
\end{abstract}

Keywords: Chitosan, grafted gel, ultrasonic radiations, crude oil

\section{Introduction}

Polysaccharide biopolymers are employed as an adsorbent because of their complex polymeric structure having reactive functional groups such as hydroxyl, amine or acetamide etc. The natural abundance, renewable nature, low cost and biodegradability of these natural opens the vista for their application as adsorbent in a various area. Chitosan, a heteropolymer is obtained by partial alkaline deacetylation of chitin and is second most abundant biomaterial, obtained from in the exoskeleton of crabs, arthropod prawns, lobsters and shrimps [1]. It has interesting chemical properties such as hydrophilicity, biodegradability, antibacterial activity and adsorption potential [2]. Chemical modification of chitosan helps to improve the solubility characteristics and adsorption properties of chitosan. Polymeric hydrogels are 3D networks of hydrophilic polymeric chains containing a large amount of water permeability to variety of molecules along with good biocompatibility and their ability as adsorbent was studied by different researchers [3-5]. The polymeric networks are able to absorb water duet o hydrophilic functional groups attached to polymer backbone and are resistant to dissolution due to cross links between network chains. The hydrogels are wide range of applications in the field of environmental and biomedical [6-7].

The focus of the present work is the greener synthesis of chitosan/acrylic acid from vinyl monomer acrylic acid grafting gel and its application as drying agent for organic solvent and crude oil fraction.

\section{Experimental}

\subsection{Material and method}

Chloroform (Ranbaxy), Cyclohexane (Rankem) and Toluene (Rankem), Petrol and Diesel (Longowal petrol pump) were used as received.

FTIR spectra of synthesized chitosan based gel (CA/AA) were recorded on Perkin Elmer-RXI FT-IR. Thermo gravimetric analysis (TGA) was carried out using TG/DTA 6300, SII EXSTAR 6000 fewer than 50 to 
$700^{\circ} \mathrm{C}$ range with heating rate of $10^{\circ} \mathrm{C}$ min-1. X-Ray Diffraction (XRD) was recorded using Philips Xpert diffractometer (Almelo, Netherlands) with monochromatic $\mathrm{CuK} \alpha$ radiation operating at $40 \mathrm{kV}$ and $20 \mathrm{~mA}$.

\subsection{Ultrasound Assisted Synthesis of CA/AA Hydrogel}

Grafted gel was prepared by dissolving $0.5 \mathrm{~g}$ of chitosan in $3 \%$ acetic acid followed by the addition of acrylic acid. Potassium per sulphate was added drop wise into the polymer solution and mixture was kept under the Sonicator bath of $40 \mathrm{KH}$ sound wave frequency. The gel obtained was washed with millipore water to remove homopolymer and the synthesized gel was dried in oven at $60 \mathrm{oC}$ till a constant weight was obtained and percent swelling (Ps) was calculated using following equation [8-9].

$$
\text { Ps }=\frac{w s-w a}{w d} \times 100
$$

Where Ws and Wd are the swelled weight and dry weight respectively.

\subsection{CA/AA as drying agent for organic solvents and crude oil}

Water absorption capacity of the gel was investigated in different organic solvents - water emulsions and oil-water emulsions for its applications as drying agent. Experiments were carried out by using chloroformwater, Cyclohexane -water, toluene-water, petrol-water, and diesel-water at temperature $\left(25^{\circ} \mathrm{C}\right) .50 \mathrm{mg}$ of chitosan based dried hydrogel was immersed in $100 \mathrm{ml}$ emulsion. The emulsions have been obtained by continuous shaking mixtures (9:1) in an automatic shaking machine. Weighing of the samples was carried-after $2 \mathrm{~h}$ time interval a

\section{Results and Discussion}

Polymerization reaction between chitosan and vinyl monomer acrylic acid takes place on exposure to ultrasonic radiations. The initiation of reaction involves the formation of free radicals $\left(\mathrm{OH}^{*}\right.$ and $\left.\mathrm{SO} 42-*\right)$ due to high pressure and temperature induced by cavitations process. The acrylic acid grafted on to chitosan is represented in figure (1). The synthesized gel was characterized by different physico-chemical techniques.

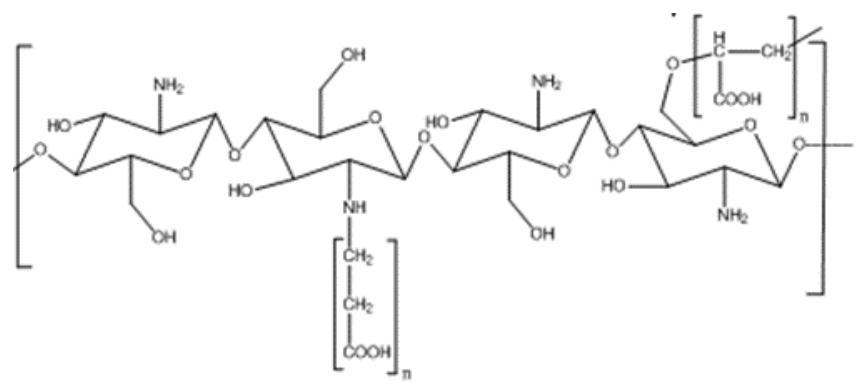

Fig. 1 Acrylic acid grafted chitosan (CA/AA)

The FTIR a spectrum of synthesized CA/AA (Fig. 2), a sharp peak at $3423 \mathrm{~cm}-1$ has been corresponds to $\mathrm{COOH}$ groups of acrylic acid polymer. The peak around $1662 \mathrm{~cm}-1$ and $1458 \mathrm{~cm}-1$ corresponds to $\mathrm{CO}$ and $\mathrm{NH} 3$ stretching vibration. The characteristic peak at $1052 \mathrm{~cm}-1$ corresponds to $-\mathrm{OH}$ groups. 


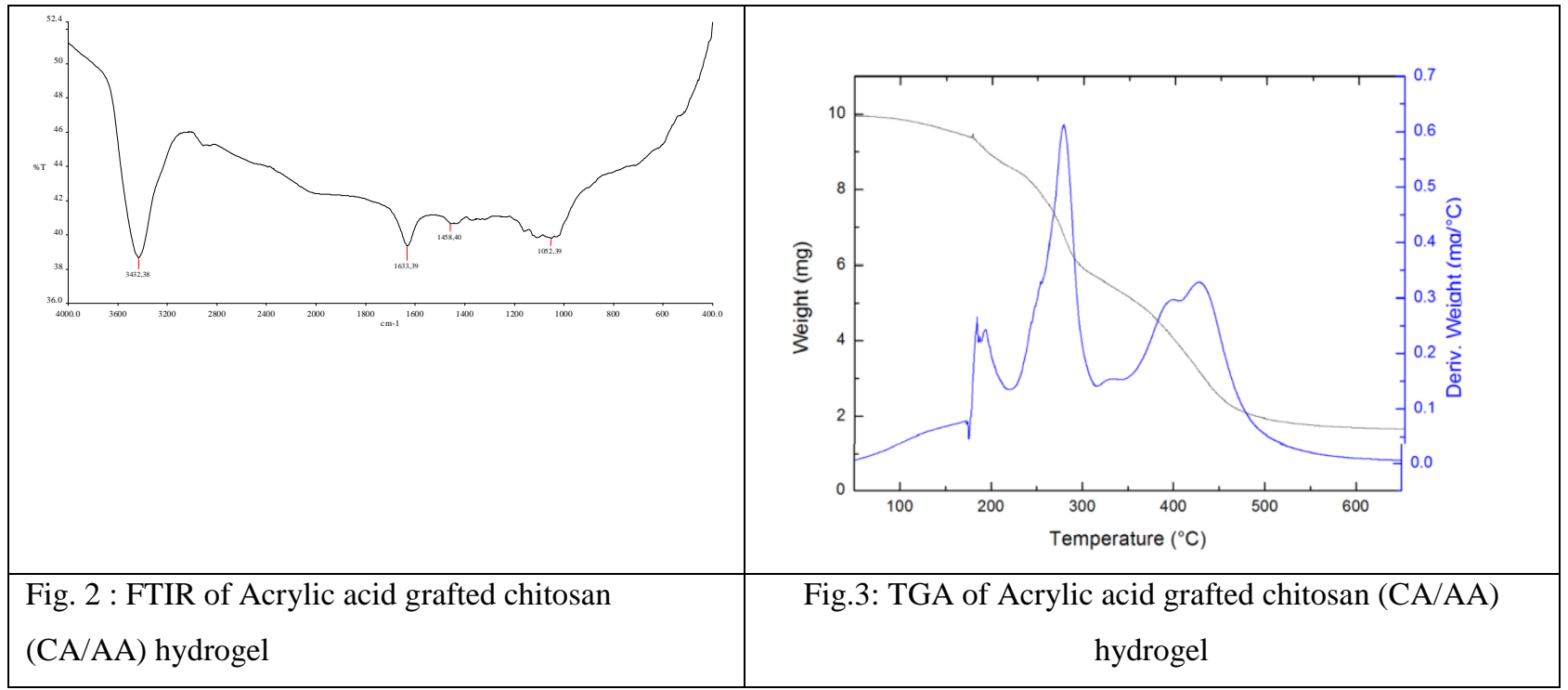

Thermal analysis TGA of grafted hydrogel is shown in Fig. 3. TGA curve of CA/AA adsorbent exhibits well differentiated weight loss steps. The first step at $150.9 \mathrm{oC}$ corresponds to loss of water molecule (2\%). The initial decomposition temperature of CA/AA adsorbent corresponds to $291.7 \mathrm{oC}$ with (40\%) weight loss and final decomposition temperature at $480 \mathrm{oC}$ with $1.8 \%$ polymeric mass were observed. Decomposition at higher temperature corresponds to breakdown of grafted chains and backbone along with other side chains.

Fig. 4 shows the XRD pattern for chitosan based grafted hydrogel. X-Ray diffractogram shows the presence of a broad band which reflected the amorphous nature of grafted gel.

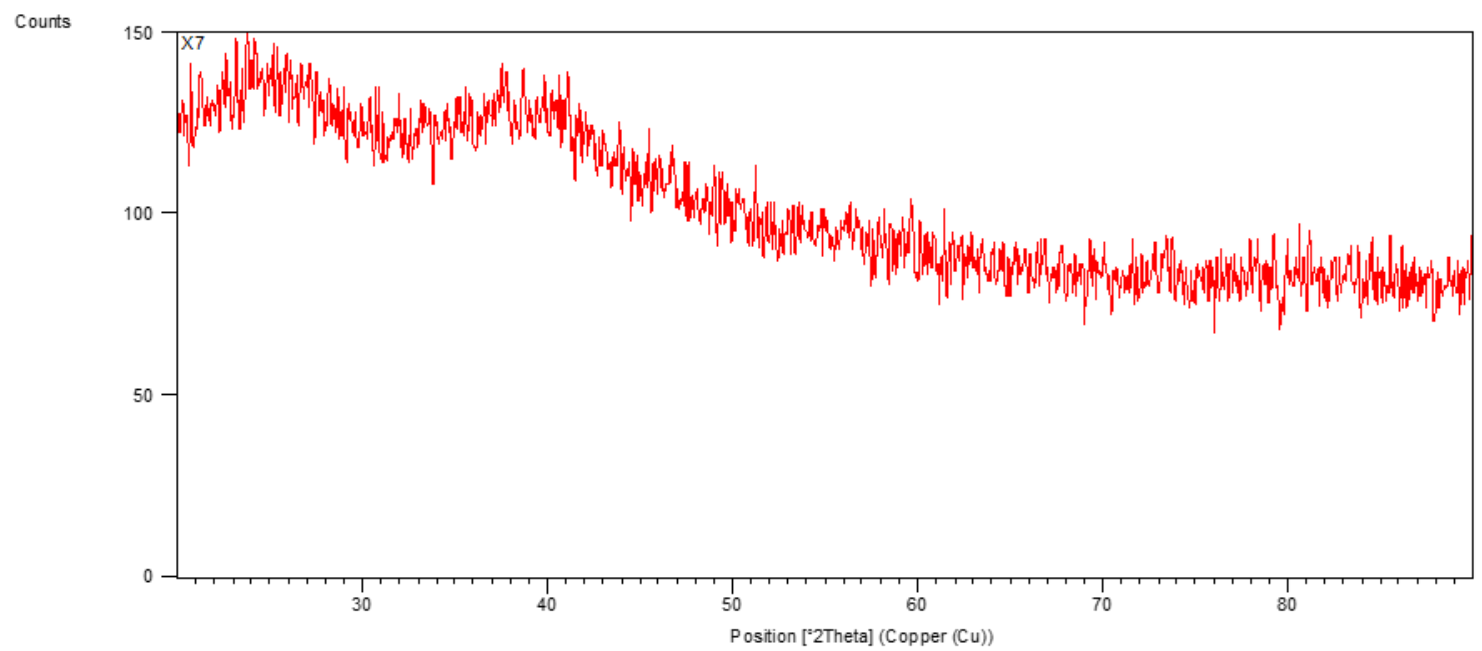

Fig. 4: XRD of Acrylic acid grafted chitosan (CA/AA) hydrogel

This confirmed the grafting of poly (acrylic acid) chains onto backbone chitosan which has crystalline structure. 


\subsection{Swelling Behavior of Hydrogel}

The swelling of CA/AA gel was observed for $24 \mathrm{hr}$ and swelling up to $550 \%$ was noticed in distilled water at $250 \mathrm{C}$. The swelling behavior of the gel is due to networks formed and reflected the hydrophilic nature of the synthesized hydrogel. The hydrophilic property was used to assess their potential as drying agent.

Water absorption studies of different emulsions of organic solvents/petroleum fractions and water, were carried out at fixed time of $2 \mathrm{hr}$ and after $2 \mathrm{hr}$ complete water removal was observed from different solvent: chloroform-water (99.9\%), Cyclohexane -water (99\%), toluene-water (99\%), petrol-water (100\%), diesel-water (100\%) from emulsions were observed.eg

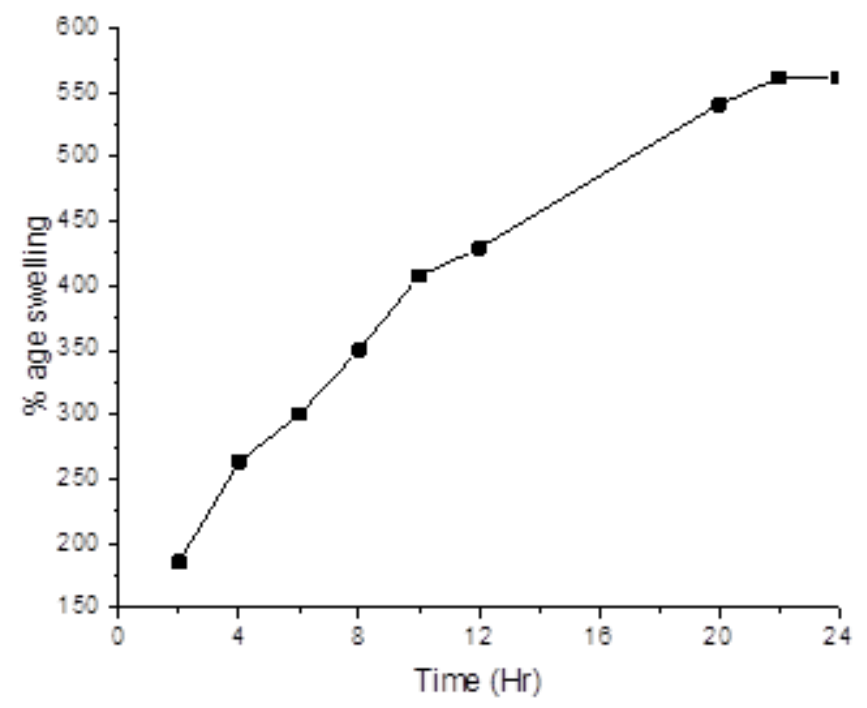

Fig. 5 Swelling behavior of grafted chitosan (CA/AA) hydrogel

\section{Conclusion}

Chitosan -acrylic acid hydrogel was prepared by polymerization of chitosan with monomer acrylic acid in the presence of initiator (K2S2O8) upon exposure to ultrasonic radiations. This study confirmed the high absorption of water from different solvents and petroleum fractions and can be employed as drying agent for organic solvents and crude oil fractions.

\section{References}

[1] Chu, K. H. (2002). "Removal of copper from aqueous solution by chitosan in prawn shell: adsorption equilibrium and kinetics, ” Journal of Hazardous Materials, 90(1), 77-95. http://dx.doi.org/10.1016/S0304-3894(01)00332-6

[2] Guibal, E. (2004). "Interactions of metal ions with chitosan-based sorbents: a review,"Separation and Purification Technology, 38(1), 43-74.

[3] Ostrowska-Czubenko, J., Pieróg, M., \& Gierszewska-Drużyńska, M. (2011). "Equilibrium swelling behavior of crosslinked chitosan hydrogels," Polish Journal of Applied Chemistry, 55(2), 49-56.

[4] Kishida, A., \& Ikada, Y. (2001). "Hydrogels for biomedical and pharmaceutical applications," Polymeric biomaterials, $133 \breve{G} 145$

[5] Camarillo, R., Llanos, J., García-Fernández, L., Pérez, Á, \& Canizares, P. (2010). “Treatment of copper (II)-loaded aqueous nitrate solutions by polymer enhanced ultra filtration and electro deposition,"Separation and Purification Technology, 70(3), 320- 
[6] Mekonnen, T., Mussone, P., Khalil, H. and Bressler, D., 2013. Progress in bio-based plastics and plasticizing modifications. Journal of Materials Chemistry A, 1(43), pp.13379-13398.

[7] Rinaudo, M., 2006. Chitin and chitosan: properties and applications. Progress in polymer science, 31(7), pp.603-632.

[8] Kaith, B.S., Singha, A.S. and Sharma, S.K., 2003. Graft copolymerization of flax fibers with binary vinyl monomer mixtures and evaluation of swelling, moisture absorbance and thermal behavior of the grafted fibers. Journal of Polymer Materials, 20(2), pp.195-200.

[9] Chauhan, G.S., Bhatt, S.S., Kaur, I., Singha, A.S. and Kaith, B.S., 1999. Modification of natural polymers: Graft copolymerization of methyl methacrylate onto rayon fiber initiated by ceric ions-A study in swelling and thermal properties. Journal of Polymer Materials, 16(3), pp.245-252. 